\title{
Dealing With Alternatives*
}

\author{
Lucia M. Tovena, \\ Université Paris VII, UMR7110CNRS \\ tovena@linguist.jussieu.fr
}

\begin{abstract}
Traditionally, pure additive particles and scalar additive particles are both characterised by an existential presupposition. They differ insofar as the set of alternatives that is built is unordered for the former, and ordered for the latter, which carry the so-called scalar presupposition. As a result, the two characterisations cannot be cumulated, an impossibility that is at odds with the fact that several languages exhibit this combination of readings for a single item. The discussion of Italian neanche '(n)either/(not) even', an item that can both be additive and scalar, allows us to expose the connection between the oppositions nonordered vs ordered set of alternatives and verified vs accommodated existential presupposition by adding content to the traditional view that the set of alternatives is made up of 'relevant' items in the context. The question of how to characterise this item is set against the backdrop of a more general discussion of the network of additive particles found in Italian.
\end{abstract}

\section{Introduction}

Adding PURE ADDITIVE and SCALAR-ADDITIVE particles to an utterance makes a clear difference to its interpretation, but exactly how to capture this difference is a matter still open to debate. It is customary to assign to pure additive and scalar-additive particles a pragmatic content which mainly takes the form of felicity constraints. Accordingly, these particles have in common an EXISTENTIAL PRESUPPOSITION (Karttunen and Peters 1979, König 1991), i.e. the associate (Krifka 1998) is understood as a member of a class of alternative individuals or actions containing at least another member.

They differ in at least two respects, both concerning the set constituted by the associate and its alternatives. First, pure additive particles such as either are assumed to have an unstructured set of alternatives. Mary's turning down the offer is neither more nor less unexpected than Jane's in example (1a). On the contrary, scalar-additive particles such as even are assumed to impose an order on the set of alternatives. This is called the SCALAR PRESUPPOSITION. Olga's not accepting in (1p) is understood as less probable/ likely/ expected/ informative than somebody else's.

(1) a. Mary turned down the offer and Jane didn't accept either.

b. Even Olga didn't accept.

A second traditional assumption is that only scalar-additive particles can accommodate their alternatives. Pure additive particles must verify their existential presupposition in the context (Zeevat 1992), see the contrast in (2).

*Thanks to Francesca Tovena, Jacques Jayez and Piermarco Cannarsa for valuable discussions. Results reported in the text are part of ongoing research. 
(2) a. ??Also Mary came.

b. Jane came. Also Mary came.

c. Even Mary came.

The discussion of Italian neanche, an item that can both be additive and scalar, allows us to expose the connection between the two oppositions nonordered vs ordered set and verified vs accommodated presupposition by adding content to the traditional view that the set of alternatives is made up of 'relevant' items which can be checked in the context.

A first factor that opens the way to the possibility of having both readings is the fact that an item does not impose a specific strategy for satisfying the existential presupposition shared by additive and scalar items, namely verification or accommodation. Another factor contributing to the same possibility is that, as far as the item itself is concerned, no specific structure is required to be detected on the class of alternatives.

It is important to notice that the type of accommodation that is relevant for the additive scalar particles under consideration is not the classic conversational case whereby a sentence like $I$ will be late because I have to drive my sister to the dentist is interpreted under the precondition of admitting as backgrounded information my having a sister when such a piece of information had not been previously provided. In the case at hand, first, there is no flavour of having, at a given time, to update a previous belief state, and second, the sentence does not contain a description of what has to be accommodated, which is to say of the alternatives. Thus, it is somewhat different also from the classical lexical case of accommodation, whereby a verb such as stop in a sentence like He stopped smoking triggers the presupposition of a change of state and the $V$-ing expression constrains what has to be accommodated. In the present case, there is no similar direct constraint and what is available is information mainly on the associate, which is to say on the entity with respect to which something can get its status of alternative and thereby be accommodated. In (Tovena 2005a) it has been proposed that imposing an order is a way of constraining the possible increase of information triggered by the additive nature of the item in the absence of overt antecedents. Thus, accommodated alternatives are not taken to be individually 'as much contextually relevant as' verified ones. Equal status in a discourse has to be gained, if ever, thanks to an explicit subsequent increase of information.

The paper is organised as follows. Aspects of the hypothesis of a connection between the strategy for satisfying the existential presupposition and the readings are presented in section 2 relatively to neanche. Section 3 aims at spelling out features of the picture that has emerged. Next, the hypothesis is tested on purely additive and purely scalar items, showing how different choices can be specified for different items and result in different combinations. Section 4 discusses some items that require the existential presupposition to be verified in the context. Section 5 deals with items that accommodate. Then, in section 6 , we will show how the line of discussion taken in the paper allows us to integrate in the picture the case of an item that is evaluative in the sense of (König 1991), but that can work also as scalar. Section 7 summarises.

\section{Underspecified strategy: neanche}

\subsection{The item}

Neanche is an Italian adverb that exhibits additive (3) and scalar (4) interpretations.

(3) Non ha mangiato la mela e neanche la pera

s/he didn't eat the apple, neither the pear 
(4) Non ha mangiato neanche il caviale s/he didn't even eat caviar

The two interpretations do not correlate with distributive differences, a fact that provides evidence in favour of a unified analysis and goes against postulating some form of lexical split for neanche. More support for this line of analysis comes from the observation that such a combination of readings for a single lexical form is not unusual, cf. (König 1991).

Historically, neanche originates from the combination of a negative conjunction and the positive additive adverb anche 'also'. It occurs in negative clauses only, cf. (5)-(7).

(5) $*$ Ha mangiato la mela e neanche la pera

s/he ate the apple and NEANCHE the pear

(6) *Non ha mangiato la mela e ha assaggiato neanche la pera

s/he didn't eat the apple and tried NEANCHE the pear

(7) *Ha mangiato neanche il caviale

s/he ate NEANCHE caviar

Let us point out that in Italian, there are two more items besides neanche that, roughly speaking, have similar distributions and interpretations, at least for the purposes of this paper. One item is neppure, which also originates from the fusion of a negative component with a positive additive adverb (pure 'also'), and the other is nemmeno. We focus on neanche because its positive component is standardly not emotionally loaded.

Exploiting the proposal put forth in (Tovena 2005a) for neppure, we characterise neanche and its siblings as particles specialised in adding negative information. This function requires that parallel information of negative nature be conveyed by an antecedent/the context and by the clause that hosts the particle. Items performing this function can be found in various languages, see for instance the English item either and French non plus. The specific syntactico-semantic properties of such items, which is to say the issue of the lexicalisation of the function in a particular language, is an independent question, albeit closely connected. Tovena (2005b) has provided clear evidence in favour of an analysis of neanche and its siblings as negative concord (NC) words. For instance, they contribute sentential negation from preverbal position (8). As it is standard for the NC system of Italian, the verbal form following the NC-word must not be negated (9). This type of lexicalisation warrants that the clause in which it occurs is always negative since either neanche belongs to a negative concord chain or it expresses negation on its own.

(8) Neanche il caviale era di suo gradimento not even caviar was fine for her/him

(9) *Neanche Daniele non ha fatto i compiti

NEANCHE Daniele didn't do the homework

The fact that neanche is interpreted as negative in self-standing occurrences and fragment answers, cf. (10), provides evidence specifically against a characterisation as a negative polarity item (NPI). NPIs are never allowed in this context with their polarity sensitive reading, see alcunché 'anything' and anybody in (11).

(10) a. Daniele non verrà, e Luisa? Neanche lei.

Daniele will not come, and Luisa? Neither 
b. Ha mangiato almeno il caviale? Neanche quello. did s/he eat caviar at least? Not even that

(11) a. Cosa fa? *Alcunché. what does s/he do? ALCUNCHÉ

b. Who will come? \#Anybody. ( $\neq$ nobody)

Furthermore, neanche is not 'licensed' in traditional NPI licensing contexts such as under negative predicates (12a), in questions (12b), in conditionals (12k), in concessive contexts such as troppo Adj (too) as in (12d).
a. $\quad *$ Dubito che abbia mangiato neanche la pera
I doubt s/he ate NEANCHE the pear
b. *Ha mangiato neanche la pera? did s/he eat NEANCHE the pear?
c. $*$ Se mangia neanche la pera, la situazione è grave if s/he eats NEANCHE the pear, it is a serious situation
d. $\quad *$ Sembra troppo stanco per fare neanche i compiti he seems too tired to do NEANCHE the homework

\subsection{Two readings}

Example (3) provides a clear case of additive reading, under the assumption that apples and pears are not ordered. The associate in (4) is traditionally viewed as more sophisticate/ exquisite/rare/ expensive than much other food, in short as ranking high in some classification. Hence it suites the intended scalar reading.

Consider now a situation where ranking is not lexically/culturally marked but information about a relevant order may be provided in the context. The background we are going to use all along is the following: Marzia, April, May, June and Julia are students who sat the same exam. Their names are listed giving the least gifted person first and the most gifted last.

Scenario 1: Marzia, April, May and June didn't pass

Consider the sentences in (13) and (14). Agent $a$ may use either of them to communicate information on the situation to agent $b$.

(13) Non sono passate Marzia, June, April e non è passata neanche May. Marzia, June and April didn't pass, neither did May

(14) Non è passata neanche June. even June didn't pass

Despite the difference in their asserted content, both (13) and (14) convey the information that Marzia, April, May and June failed the exam. How does $b$ get it? Directly in (13), where all the alternatives are overtly provided and the set can be freely 'scrambled', see its equivalent in (15). Indirectly in (14), by exploiting the understanding that the girls are not equally gifted and their performances are going to reflect this situation. This leads to the interpretation whereby the girl who is mentioned is the cleverest among those who didn't pass.

(15) Non sono passate Marzia, April, May e non è passata neanche June.

Marzia, April and May didn't pass, neither did June 


\subsubsection{Computing the set of alternatives}

Given the proposition $\alpha(\beta)$ expressed by sentence $S$ where neanche occurrs with $\beta$ as its associate, the existential presupposition that characterises additive items is traditionally given as in (16).

$$
\exists y[\alpha(y) \wedge y \neq \beta]
$$

This presupposition is meant to express the general understanding that the associate is viewed as a member of a class, that is the set of alternatives. On the one hand, the value for $y$ must be comparable to the associate in some respect. For instance, in (3) one considers names of people, and food in (4). On the other hand, $\alpha$ is thought of as something that takes an object of the same type as $\beta$ as an argument and returns a proposition true in the context as it does with $\beta$.

There are at least two problematic issues to consider. First, proposing a general treatment for $\beta$ is not an easy task, because neanche, as many other particles, can take associates of various types, e.g. NPs, VPs, PPs, etc. We won't pursue this side of the investigation in the paper. Second, $\alpha$ may not be directly available, either because neanche and its associate occur in an elliptic structure so that the host clause does not provide enough content, cf. (17) there is no overt antecedent against which to check what gets into $\alpha$, cf. (18).

(17) La vittima non ha incontrato Luisa. E neanche Daniele.

the victim did not meet Luisa. And she didn't meet Daniele either

the victim did not meet Luisa. And neither did Daniele

(18) La festa è stata un disastro. Sembra che alle due non fosse ancora venuto neanche Daniele.

the party was a complete failure. It seems that by 2 a.m. not even Daniele had showed up yet

Furthermore, $\alpha(\beta)$ and $\alpha(y)$ may be true although $\alpha$ cannot be made to correspond to identical lexical material in the host clause and the antecedent clause, as noted for either by Rullmann (2003), cf. (19).

Luisa ha respinto la nostra offerta. Neanche Daniele ha accettato.

Luisa rejected our offer. Daniele didn't accept either

Traditionally, the set of alternatives triggered by an alternative inducing operator is defined following the treatment proposed by Rooth for focus operators. Rooth (1992) has claimed that the set of alternatives for the associate $\beta$ of a focus operator, the focus semantic value of $\beta$ in his terminology, is a set that contains both its ordinary semantic value, i.e. the denotation of the associate itself, and at least one element distinct from it, roughly speaking. More precisely, alternatives are considered with respect to the host clause, thus we are interested in the focus value of a clause, which is to say that we consider the set containing the proposition expressed by this clause as well as the propositions obtained by replacing focus marked material with alternatives of the same type. However, in the following we may, at times, sloppily talk of the set of alternatives as if made up of $\beta$ and its alternates.

Rooth further claims that the focus semantic value considered in a specific case is a 'relevant' subset of the focus semantic value of the clause, constrained by contextual information. For instance, in our particular setting the property 'girl' or 'human being' can be derived from the

\footnotetext{
${ }^{1}$ It is true that in the general case discourse defuses this problem.
} 
lexical content of the associate and be used to build its focus semantic value. Context can restrict the set of possible alternatives obtained in this way, so we can also consider properties like 'student' and 'sitting the exam' in our setting. Most importantly, the propositional function expressed by the host clause, here 'did not pass' is also used.

This is Rooth's C set. We will call it $A L T_{\beta}$ because we think that it is built getting all one can get from $\beta$ but that the role of $\alpha$ has not been fully appreciated and that the set may be further constrained by it. Indeed, the restriction effect of context is stronger when linked to overt information available in the co-text. We propose that $A L T_{\beta}$ is what one can initially get with the associate and the host clause. It might contain contrasting alternatives. But verification of the existential presupposition in the context always results in double checking the set that is possibly reduced and gets (temporarily) closed. At this point, $\alpha$ too will have given us all it can contribute. We will call $A L T_{\beta}^{\alpha}$ the resulting set.

Therefore, two cases have to be distinguished. In the case of satisfaction by verification, the associate is argumentatively the upper bound of any subset of $A L T_{\beta}$ whose members are entailed by the context and end up in $A L T_{\beta}^{\alpha}$. Thereby, the associate actually is the greatest element in $A L T_{\beta}^{\alpha}$ from the vantage point of argumentation, we come back to this point at the end of the section. The definition of upper bound is recalled in (20). It is worth noticing that this notion requires $\mathrm{X}$ to have at least another member besides $x$.

(20) Let $\mathrm{X}$ be a partially ordered set and $\geq$ an order in it. Let $x \in \mathrm{X}$. Let $\mathrm{Y} \subset \mathrm{X}$. $x$ is an upper bound for $\mathrm{Y}$ iff $\forall y, y \in \mathrm{Y}, x \geq y$.

On the other hand, if no verification takes place, $A L T_{\beta}$, or presumably a subset of it, would have to be accommodated. In such a situation, using an order is the best way of building an $A L T_{\beta}^{\alpha}$ that is fit for potential future increases of information. This is because the associate is the only member which is provided, therefore it is the only one that can bear the burden of the construction of the set and is assigned the role of scalar endpoint. Thus, in the case of satisfaction by accommodation, $A L T_{\beta}^{\alpha}$ has the associate as it sole member and the extra bit of information that has to be accommodated is the constraint that the associate is a maximal element. As a matter of fact, it is 'the' maximal element. No other alternatives have to be accommodated specifically. The definition of maximal element, recalled in (21), makes it clear that this notion does not require nor warrant the existence of one or more members in $\mathrm{X}$ besides the associate.

$$
\begin{aligned}
& \text { Let } \mathrm{X} \text { be a partially ordered set, } \geq \text { an order, and } x \in \mathrm{X} \text {. } \\
& x \text { is a maximal element in } \mathrm{X} \text { iff } \\
& \forall y, y \in \mathrm{X}, y \geq x \rightarrow y=x
\end{aligned}
$$

The type of $A L T_{\beta}^{\alpha}$ that we get in this second case works as a label for the class of equivalence of the subsets of $A L T_{\beta}$ that are candidate for the role of actual set of alternatives in every situation as long as no more information is available. Speaker and hearer may even entertain different options. No specific subset of $A L T_{\beta}$ is selected as information that is accommodated, i.e. when building $A L T_{\beta}^{\alpha}$ an agent does not commit herself to a position stronger that what can be warranted and does not run the risk of having to retract. At the same time, information is incremented all the same.

Summing up, $A L T_{\beta}$ is made of potential alternatives. $A L T_{\beta}^{\alpha}$ is the actual set of alternatives. It seems plausible to treat $A L T_{\beta}$ as the product of the focus component of a particle and $A L T_{\beta}^{\alpha}$ as the product of the (pure and scalar) additive component. This hypothesis will not be tested in the following, but it may help to formulate a characterisation for the evaluative particle discussed 
in section 6 ,

In a short aside, we note that extra complications come from the fact that 'contradicting' information may be subsequently added to what contributed by $A L T_{\beta}$ and $A L T_{\beta}^{\alpha}$ to a discourse, but a retraction indicator of some kind must be used, for instance neanche is repeated in (22). However, such a revision is more easily done when neanche is used as an additive particle than as a scalar one, see the marginal status of sequencing in the micro discourse proposed in (23).

(22) Non c'era Luisa e neanche Daniele. E neanche Gianni, adesso che ci penso.

Luisa was not there, neither was Daniele. Neither Gianni, I recall it now.

(23) Figurati che fiasco, non c'era neanche Luisa. ? E neanche Daniele.

Just think of the flop, not even Luisa was there. And not even Daniele.

We can make sense of this situation if we recall that $A L T_{\beta}^{\alpha}$ is built extensionally, so that in $(22)$ the revision amounts to reopening the set and adding one extra element without further consequences for the structure of the collection. In the case where alternatives are accommodated, on the contrary, revision involves computing the set afresh, because it is the new element that has to work as scalar endpoint and the scale must include the previous associate.

Finally, we should also cash in the effect that comes from the argumentative purpose of sentences containing additive and scalar particles. The argumentative goal provides a perspective on $A L T_{\beta}^{\alpha}$ that translates in a relevance based (partial) ordering that is always imposed on $A L T_{\beta}^{\alpha}$ at the discourse level. Extending to neanche the claim made in (Tovena 2005a) about neppure 2 we say that in uttering a sentence containing neanche:

- The speaker signals that the piece of information added via the host clause is going to lead to modifications in the information state that would not occur without such an addition.

- The modification has a particular discoursive function, therefore the presence of neanche triggers a search for a discourse goal by the hearer.

- The particle marks the piece of information as precisely the one that was missing to get the intended effect.

The piece of information provided via the associate is maximally useful/relevant for the argumentative goal in the scalar as well as in the additive cases.

\subsubsection{The additive reading}

Let us go back to our examples 13 and 14 . In our setting, $A L T_{\beta}^{\alpha}=\{$ Marzia, April, May, June $\}$ or rather $<$ Marzia, April, May, June $>$.

We have assumed that to get the additive reading, the alternatives are identified using the associate and the content of the host clause in an anaphora-like way (van der Sandt 1992). The existential presupposition is satisfied only by verification, i.e. if and only if the proposition expressed by the host sentence with an alternative substituted for the associate follows from the context.

It is worth emphasising that in (3), where no order is perceived, as well as in (15), where a contextually given order was assumed, the associate is treated on a par with the alternatives. It is the context that provides overt information supporting the move from one member to the other required to build the set of alternatives $A L T_{\beta}^{\alpha}$.

The behaviour of additive neanche is captured by condition (24).

\footnotetext{
${ }^{2}$ Analogous considerations can be found in proposals put forth by (Merin 2003, Van Rooy 2003).
} 


\section{(24) constraints on neanche}

(i) $A L T_{\beta}^{\alpha}$ can be a partially ordered set

(ii) $A L T_{\beta}^{\alpha}$ is always argumentatively partially ordered

(iii) the associate of neanche is argumentatively the maximal element in $A L T_{\beta}^{\alpha}$

(iv) if $A L T_{\beta}^{\alpha}$ is ordered, the associate the maximal element in it, because this order must be compatible with the argumentative order.

Summing up, a first case is that of (3) where there are overt antecedents, no perceived order, and neanche gets an additive reading. A second case is exemplified by (15). Here we observe the presence of overt antecedents but this time neanche can get a scalar reading. This is so because $A L T_{\beta}^{\alpha}$ happens to be a chain due to information provided in the setting. This possibility is allowed by (24 v). Analogously, in (25) we find overt antecedents and a scalar reading, since $A L T_{\beta}^{\alpha}$ happens to be totally ordered because of lexical information. Cultural information may also be taken into consideration for establishing an order, see (26). Example (26) shows that for an order to be perceived it is not necessary that the antecedent clause is entailed by the host clause 3

(25) Non ha studiato questo capitolo, e non l'ha neanche letto

He didn't study this chapter and he did not even read it

(26) Non ci ha ringraziato e non ci ha neanche salutato

He didn't say 'thanks' and did not even say 'hello' to us

\subsubsection{The scalar reading}

Examples (15) and (25)-(26) show that the scalar reading can emerge in the presence of overt antecedent(s) if an order is perceived in the set of antecedents. Well formedness is not affected by (non-)perception.

The next case to consider is that of (14), where there are no overt antecedents and neanche gets a scalar reading. Given the information provided in the background, we know that in our setting $A L T_{\beta}$ is a chain. The possibility for neanche of having a scalar reading in this case is also captured because condition (24iv) is sensitive to the structure of $A L T_{\beta}$.

Suppose now that the background is not overtly stated. If there are no antecedents, the class is still constrained via information on the discoursive role of the associate, but $\alpha$ and information coming from $\beta$ cannot be used for verifying the existential presupposition. Here is where the change in the strategy for satisfying this presupposition is needed. The only way of bringing in relevant candidates for a set of alternatives, i.e. of controlling the move from the associate to some alternative(s), is by reasoning by abduction on $(24 \mathrm{iv})$ and the fact that no alternatives are provided in the context. The associate is required to be an upper bound for a potential subset $A L T_{\beta}^{\alpha}$ but several such subsets can be envisaged. It is the greatest element of a partial order. For instance, example (14) per se is compatible also with a scenario where the names are ordered by luck, good shape, likelihood to succeed, etc. Several sets of alternatives might be entertained as the result of accommodating different ordering relations. Indeed, different agents may entertain different options in the same context, a situation that need not lead to a break down in communication because the crucial role of the associate is shared by them all. The possibility of conceiving different scales is covered by the current analysis, where the set of alternatives is defined only intensionally whenever the existential presupposition is not satisfied by verification.

\footnotetext{
${ }^{3}$ Thanks to Manfred Krifka for pointing this out.
} 


\subsection{Unconventional scales}

The fact that the information contributed has to be maximally relevant for a specific goal, and not in absolute terms, makes it possible to account for scalar cases where the associate is not a standard scale endpoint, see (27). Given the physical or mental shape of the athlete, it was possible for her to win the semifinals and possibly the finals. When it comes to evaluating her performance, information that she did not make it to the final is more relevant than knowing that she didn't win it.

Non ha vinto neppure la semifinale!

s/he did not win even the semifinals

The scale under consideration is not the one made up by the steps of a traditional tournament, but the one made by the levels the athlete could have reached.

\section{Tacking stock on additive particles}

In short, the key idea is that a particle that has an additive reading must verify the existential presupposition. Italian anche, English either and also are all well behaved members of this class.

As a first point, we record this aspect of the behaviour common to all additive particles as a constraint, in (28). This constraint is standardly met by verifying the existential presupposition and evaluating the impact of the particle at the discourse level.

(28) Constraint 1 on additive particles

The set of alternatives $A L T_{\beta}^{\alpha}$ of an additive particle is not ordered directly by the particle, but argumentatively the associate is understood as the maximal element in it.

Next, we have noted that a lexical item may allow the possibility of taking into consideration the structure of the set of which the associate is maximal even if it does not impose specific requirements on it. This is to say that the presence of an order may be visible even when the order is not required. However, if there is an order, the associate is the greatest upper bound, and as such it could help in reconstructing the set when there are no overt antecedents. Hence, an ordering relation is taken into consideration to control the satisfaction of the existential presupposition by accommodation.

Neanche leaves unspecified the strategy for satisfying the existential presupposition. This can be satisfied by verification in context or by accommodation by working out the composition of the set of alternatives from the associate, which is the maximal element.

The possibility of accommodating correlates with the crucial role that the associate plays when the set of alternatives is constituted. We record this point as a constraint, in (29).

Constraint 2 on additive particles

$A L T_{\beta}^{\alpha}$ is an ordered set $\Leftrightarrow$ the associate is the greatest upper bound for it.

The constraint in 29) is shared by neanche and all additive-scalar particles.

Finally, let us observe that $A L T_{\beta}^{\alpha}$ can be totally ordered in two cases: (i) when $A L T_{\beta}$ is totally ordered due to contingent facts, and (ii) when the associate is required to be the upper bound for $A L T_{\beta}^{\alpha}$, although the order is not always total. The latter is the scalar case. The former is discussed in the second half of the next section. 


\section{Specific strategy-verification: anche, also}

In the case of well behaved additive particles such as also, we have just said in the previous section that the associate is a maximal element in order to satisfy its argumentative/discoursive function, but that the existence of antecedents, due to the existential presupposition, does not come with the requirement of an order. The existential presupposition is an independent requirement and its satisfaction does not involve imposing or even just appealing to any ordering relation. The same applies to Italian anche, with the only difference that this item is not equally 'blindly' well behaved, as we will see shortly.

It is then important to establish two points with certainty. First, we must know whether it is indeed the case that verification of the existential presupposition always takes place with additive particles. In order to test this, we can check if antecedents are always present in the preceding co-text, as usually claimed. A preliminary corpus-based study on anche confirms this claim and reveals that exceptions are rare and tolerated only when the context provides an unambiguous and usually unique alternative. Two possible cases are recorded.

1. The alternative is a widely known public figure particularly salient at the time the sentence is produced. Since the alternatives are identified in an anaphora-like way on extralinguistic material only, the success of the operation is uncertain and the felicity of the utterance decades fairly rapidly. At the time (30) was printed on a newspaper as the first sentence of an article, the antecedent, i.e. the death of the Pope, was in everybody's mind. Just a few months later the sentence may already sound awkward.

(30) Anche il principe Ranieri di Monaco, 81 anni, è morto [...]. (IM7-4-2005) also Prince Ranieri of Monaco, aged 81, has died

2. The antecedent is the speaker, and this seems to apply to direct or reported speech. Example (31) is made of the title, the subtitle and the beginning of the first paragraph of an article from a newspaper. It contains an instance of this phenomenon with neppure (1), an instance with anche (2), and a regular additive use of neppure (3).

(31) (1) Neppure la Fiat vuole l'intervento dello Stato «L'azienda non è interessata», dice Maroni dopo l'incontro con Marchionne.

(2) Anche i vertici della Fiat sarebbero contrari all'ingresso dello Stato nel capitale della multinazionale dell'auto. A riferirlo è stato ieri il ministro Maroni, dopo l'incontro con l'amministratore delegato del gruppo, Sergio Marchionne, a Palazzo Chigi: un intervento dello Stato nel capitale Fiat, ha detto il ministro, sarebbe «inutile, dannoso e, lo dico da stasera, non gradito. (3) Su questo intervento oltre a non essere d'accordo il governo non lo è infatti neppure Fiat».(IM10-2-2005) $)^{4}$

(1) Fiat does not want the intervention of the state either

Maroni says [...]

(2) Fiat's top management too would be against the State taking a stake in the capital of the multinational car manufacturer. It is the minister Maroni who said this yesterday, $[\ldots]$

(3) Concerning this intervention, besides the unwillingness of the government, there is also that of Fiat.

\footnotetext{
${ }^{4}$ Numbers have been added to ease reference.
} 
We conclude that it is indeed the case that plain additive particles require the verification of the existential presupposition in context. ${ }^{5}$

Second, it is important to have a way of telling apart items that leave the strategy underspecified, like neanche, from additive items that must always verify the existential presupposition but can still have emphatic scalar readings due to the contingent fact that $A L T_{\beta}$ happens to be totally ordered, like anche. As discriminating test, we propose to use the case of a gap in an order. Only the latter type of particles are compatible with a scenario where the chain $A L T_{\beta}^{\alpha}$ has a gap relatively to the chain in $A L T_{\beta}$, because the antecedent tells us where the gap is. On the contrary, scalar inferences used by scalar items to work out possible sets $A L T_{\beta}^{\alpha}$ from the associate alone are built monotonically.

Consider the usual background.

Scenario 2: Suppose it has just been disclosed that May, June and Julia passed the exam. The exam was very difficult and not many people were expected to pass.

Surprise can be expressed with scalar perfino (positive even) and stressed anche, see (32)-(33). Mutatis mutandis, surprise can be expressed with neanche, see (34).

Perfino MAY è passata?

did even May pass?

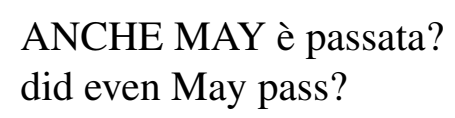

Non è stata bocciata neanche MAY?

did May not fail either?

Scenario 3: Suppose instead that June also failed. (Recall that we are dealing with pragmatic scales.)

In this scenario, May is the maximal element in $A L T_{\beta}^{\alpha}$ and the structure of this set preserves the order of the chain in $A L T_{\beta}$ of which May is an upper bound. The specificity of the case is that the new chain, i.e. $A L T_{\beta}^{\alpha}$, is a subset of that present in $A L T_{\beta}$. In this case, only anche can still be used, see (35)-(37).

$$
\begin{aligned}
& \text { \#Perfino MAY è passata? } \\
& \text { did even May pass? }
\end{aligned}
$$
ANCHE MAY è passata?
did even May pass?
\#Non è stata bocciata neanche MAY?
did May not fail NEANCHE?

The contrast can be exlained as follows. Anche obtains $A L T_{\beta}^{\alpha}$ by verification. It is sensitive to whether there is an order on $A L T_{\beta}^{\alpha}$, which is necessarily external to the operation of building the set. The comparison with the order on $A L T_{\beta}$ can also be done independently. On the contrary, the composition of $A L T_{\beta}^{\alpha}$ predicted with perfino (and neanche in the scalar reading) by using the associate as maximal is incompatible with information coming from the context in (35) and (37). Indeed, perfino works out candidate sets $A L T_{\beta}^{\alpha}$ using the associate in this way because the existential presupposition it triggers has to be accommodated. Inferences drawn from the associate are monotone. The stumbling block is the gap represented by June's failure which

\footnotetext{
${ }^{5}$ The third possibility recorded is a case of cataphora.
} 
cannot be predicted from the succes of May.

Summing up, anche is subject to condition (38). The fact that the existence of overt antecedents must be verified is recorded in constraint $(38 \mathrm{lv})$. The option of viewing the associate as maximal in $A L T_{\beta}^{\alpha}$ - other than on argumentative ground-is not overtly stated, which may be another reason why the existential presupposition cannot be accommodated.

\section{constraints on anche}

(i) $A L T_{\beta}^{\alpha}$ can be partially ordered

(ii) $A L T_{\beta}^{\alpha}$ is always argumentatively partially ordered

(iii) the associate is argumentatively the maximal element in $A L T_{\beta}^{\alpha}$

(iv) $\left|A L T_{\beta}^{\alpha}\right|>1$ is verified in context

(v) if $A L T_{\beta}^{\alpha}$ is ordered, this order must be compatible with the argumentative order.

The difference between also and anche is then that a well behaved additive item like also works as if the status of greatest element of the associate must be ascribed only to the argumentative purpose it serves, and requires $A L T_{\beta}^{\alpha}$ to be unordered in all other respects. Instead, anche can make do with a set $A L T_{\beta}^{\alpha}$ that is ordered for independent reasons, as long as such an order is compatible with the argumentative ordering, as stated by condition $(38 \mathrm{v})$. Hence, a scalar reading is possible, but it is parasitic on an independently ordered domain. Apparently also is replaced by a specialised item when $A L T_{\beta}^{\alpha}$ is ordered.

\section{Specific strategy-accommodation: perfino, even}

Well behaved scalar items such as perfino and even always allow one to accommodate the existential presupposition, hence the associate always has to be viewed as the greatest upper bound in $A L T_{\beta}^{\alpha}$ as well as a maximal element.

Perfino is subject to condition (39).

constraints on perfino

(i) $A L T_{\beta}$ is partially ordered

(ii) $A L T_{\beta}^{\alpha}$ is always argumentatively ordered with the associate as its maximal element

(iii) the associate is a maximal element in $A L T_{\beta}$

(iv) the associate is the greatest element in $A L T_{\beta}^{\alpha}$

(v) $A L T_{\beta}^{\alpha}$ is accommodated in context

\subsection{Accommodation and contextually available resources}

Constraint $(39 \mathrm{~V})$ says that the existential presupposition has to be accommodated. However, scalar items are compatible with the presence of overt antecedents.

Luisa ha incontrato il direttore e persino il presidente

Luisa met the director and even the president

We propose that the two strategies for satisfying the existential presupposition may be independently triggered and are expected to converge when overt antecedents of scalar particles are available. This may seem an uneconomical choice that goes against the idea that accommodation is a rescue strategy. Evidence in favour of a double attempt, comes from the existence of 'exceptional' additive readings of well behaved scalar items, such as Fauconnier's famous ex- 
ample (41) concerning French même 'even'. In (41), and in the Italian corresponding sentence (42), the set of overt candidates for the role of antecedent does not exhibit a salient order, as confirmed by the possibility of commuting the elements.

(41) Georges a bu un peu de vin, un peu de cognac, un peu de rhum, un peu de calva et même un peu d'armagnac. (Fauconnier 1976, 17)

Georges drank a little wine, a little cognac, a little rum, a little calvados, and even a little armagnac

(42) Giorgio ha bevuto un po' di vino, un po' di cognac, un po' di rum, un po' di calvados e perfino un po' di armagnac.

When there is an overt but apparently unordered set of antecedents, the double attempt results in a bleached form of the scalar reading. On the one hand, particles try to verify their presuppositions in the context and, as a result, an independent additive reading can emerge. On the other hand, if no salient order is perceived, a scalar reading can still be built by accommodating an order based on quantities, since the associate is the last element of a sequence.

\section{Evaluative (scalar-like) items: addirittura}

The last item we are going to discuss in this paper is the Italian positive particle addirittura, which can be rendered only partly by English even. This item would presumably fit in the class that (König 1991) has labelled as evaluative items, as it takes an associate that must be perceived as ranking high.

Consider (43). It can be used in contexts where several people pulled strings, in which case it is equivalent to perfino, see (44), and translates as even.

(43) Per ottenere questo posto si è fatto raccomandare addirittura dal vescovo.

to get this job he got even the bishop to pull strings for him

(44) Per ottenere questo posto si è fatto raccomandare perfino dal vescovo.

to get this job he got even the bishop to pull strings for him

However, (43) is compatible also with a situation where the bishop is the only person who pulled strings, in which case tha sentence is not equivalent to (44) and the English rendering with even is no longer suitable. A better rendering is provided in (45), for which literal translations in Italian are given in 46 .

The bishop himself pulled strings for him to get him this job

Per fargli ottenere questo posto, lo ha raccomandato il vescovo $\left\{\begin{array}{l}\text { in persona } \\ \text { medesimo }\end{array}\right.$

$A L T_{\beta}$ is viewed as the product of the focus component of a particle. The fact that a sentence containing addirittura can be used felicitously in a context where the proposition it expresses does not hold for a permutation of the associate, means that addirittura does not trigger a presupposition of existence. $A L T_{\beta}^{\alpha}$ might not be computed. Hence the associate can be characterised as a maximal element in $A L T_{\beta}$ but it is not necessarily the upper bound of one of its subsets. Further evidence supporting this characterisation comes from example (47), where the bishop is considered to rank high on the scale of influential people but the indefinite article requires him to be one among several, which is still compatible with a situation where only one person 
pulled strings.

(47) Per ottenere questo posto si è fatto raccomandare $\left\{\begin{array}{l}\text { addirittura da un vescovo } \\ * \text { da un vescovo in persona } \\ * \text { da un vescovo medesimo }\end{array}\right.$

to get this job he got nothing less than a bishop to pull strings for him

Constraints imposed by addirittura concern the associate, as recorded in (48). The conditional form of (48,ii) paves the way to a scalar reading but does not have to be matched with an existential presupposition

\section{constraints on addirittura}

(i) $A L T_{\beta}$ is a partially ordered set

(ii) the associate is a maximal element in $A L T_{\beta}$

(iii) if $A L T_{\beta}^{\alpha}$ can be computed, i.e. if $\left|A L T_{\beta}\right|>1$ in context, then the associate is the upper bound of at least one of its subsets.

The need for constraint (48) ii) is exposed by the contrast in (49). The presence of suitable antecedents triggers the computation of $A L T_{\beta}^{\alpha}$, but all overt alternatives must rank lower than the associate.

(49) a. Per ottenere questo posto si è fatto raccomandare dal prete e addirittura dal vescovo to get this job he got the priest and even the bishop to pull strings for him

b. *Per ottenere questo posto si è fatto raccomandare dal vescovo e addirittura dal prete he got the bishop and even the priest to pull strings for him

\section{Summary}

We have discussed how the scalar and additive readings of neanche result from different ways of satisfying the existential presupposition in the absence of specific constraints on two choice points which are the structure of the set of alternatives and the strategy to adopt to satisfy such a presupposition.

Next, the behaviour of several items has been characterised as corresponding to different combinations of choices. When verification of the existential presupposition is required, the additive reading emerges, but the scalar reading is possible as parasitic on a set of alternatives that is ordered for independent reasons. This is the case of anche. When accommodation is selected, scalar readings are always possible. This is the case of perfino.

In order to develop a network of items, we have also exploited the different consequences that the use of the two notions of maximal and of upper bound have on the minimal cardinality of the set of alternatives. In this way, the evaluative and at times scalar item addirittura can also find its place.

\section{References}

Fauconnier, G.: 1976, Remarque sur la théorie des phénomènes scalaires, Semantikos 1, 13-36.

Karttunen, L. and Peters, S.: 1979, Conventional implicature, in Oh and Dinneen (eds), Presupposition, Volume 11 of Syntax and Semantics, Academic Press, New York, pp. 1-56. 
König, E.: 1991, The Meaning of Focus Particles - A Comparative Perspective, Routledge, London.

Krifka, M.: 1998, Additive particles under stress, Proceedings of Semantics and Linguistic Theory VIII, pp. 111-129.

Merin, A.: 2003, Replacing 'Horn Scales' by Act-Based Relevance Orderings to keep negation and numerals meaningful, Forschungsberichte des DFG-Forschergruppe 'Logik in der Philosopie'.

Rooth, M.: 1985, Association with focus, PhD thesis, University of Massachusetts at Amherst.

Rooth, M.: 1992, A theory of focus interpretation, Natural Language Semantics 1, 75-116.

Rullmann, H.: 2003, Additive particles and polarity, Journal of semantics 20, 329-401.

Tovena, L. M.: 2005a, Discourse and addition, Workshop Discourse Domains and Information Structure ESSLLI 2005, pp. 47-56. http://www.linguist.jussieu.fr/ tovena/papers/esslli05p-ref.pdf.

Tovena, L. M.: 2005b, Facets of a negative additive adverb, talk delivered at 3rd Workshop on Syntax and Semantics, Nantes.

van der Sandt, R.: 1992, Presupposition projection and anaphora resolution, Journal of Semantics 9, 333-377.

van Rooy, R.: 2003, Negative polarity items in questions: strength as relevance, Journal of Semantics 20, 239-274.

Zeevat, H.: 1992, Presupposition and accommodation in update semantics, Journal of Semantics 9, 379-412. 